\title{
EFFECTIVENESS OF CLOSED REDUCTION IN THE TREATMENT OF NASAL BONE
}

\section{FRACTURES}

\author{
Sigdel $B$, Sah $K$
}

Department of Otolaryngology \& Head and Neck Surgery, Gandaki Medical College, Pokhara, Nepal

\begin{abstract}
This study was conducted to investigate the effectiveness of closed reduction of nasal bone fracture according to severity. It was a retrospective study carried on 60 patients with mean age of 30.2 years (range 10-67 years) who have undergone a closed reduction of a nasal bone fracture at Gandaki Medical College Teaching Hospital from January 2017 to December 2019. The patient with nasal bone fracture who underwent surgical intervention with closed reduction under General anaesthesia were included in this study. Fracture severity was evaluated according to Hwang et al.'s classification method. All patients underwent closed reduction with external nasal splinting under General anesthesia. The patients were followed-up for at least three months to assess the complications, such as fracture recurrence and functional abnormality in the Department. The most common cause of nasal bone fracture was road traffic accidents 25 (41.6\%) followed by physical assaults $18(30 \%)$, fall injuries $12(20 \%)$, other incidences $3(5 \%)$, and industrial accidents 2 (3\%). Forty-three (72\%) cases underwent closed reduction within 24 hours of those who arrived within 4-6 hour of nasal injury in the hospital and the remaining 17 $(28 \%)$ cases were reduced after 5 days of trauma. Concurrent fracture found in $8(13 \%)$ cases and it included maxillary, zygomatic, orbital, frontal bone fracture. Nasal bone fracture mostly occurs in road traffic accidents. Closed reduction with good alignment is the preferred method. Septorhinoplasty and extracorporeal septoplasty should be applied in difficult and comminuted nasoseptal fracture.
\end{abstract}

\section{KEYWORDS}

Closed reduction, effectiveness, septorhinoplasty

\section{CORRESPONDING AUTHOR}

Dr. Brihaspati Sigdel,

Associate Professor \& HOD

Department of Otolaryngology \& Head and Neck

Surgery, Gandaki Medical College, Pokhara, Nepal

Email: brihassig1@gmail.com

Orcid No: https://orcid.org/0000-0002-8546-6699

DOI: https://www.doi.org/10.3126/nmcj.v23i1.36225 


\section{INTRODUCTION}

The nasal bone is the most common facial bone fracture which accounts for $40 \%$ of all facial fractures. ${ }^{1}$ The causative factors for nasal bones fracture include physical assaults, falls, sports injuries and road traffic accidents. ${ }^{2,3}$

The closed reduction attempts to approximate and align the cartilaginous and skeletal nasal structures to their pre-trauma state and to improve the airway with minimal side effects. The management of displaced nasal bone fracture should be performed with a closed reduction in the acute setting within 1 to 2 weeks period. ${ }^{4}$ Long-standing traumatic nasal deformities require formal septorhinoplasty.

Although there is an abundant amount of research on nasal bone fracture reduction, it is difficult to adopt the same treatment in our population. Aim of the study is to observe the causes, pattern and effectiveness of closed reduction by patient satisfactions grading in the treatment of the nasal bone fracture in tertiary care hospital, Pokhara.

\section{MATERIALS AND METHODS}

This is a retrospective study done in sixty patients with mean age of 30.2 years (range 10-67 years) who have undergone a closed reduction of a nasal bone fracture at Gandaki Medical College Teaching Hospital from January 2017 to December 2019. Approval for the study was obtained from the Institutional Review Board. Patient's age, gender, cause of fracture, severity of fracture, concurrent fracture, the time elapsed until operation and time after fracture, postoperative complications, and patient satisfaction grading were reviewed from ENT OPD record, ENT ward, and operation note of medical record. The patient with nasal bone fracture who underwent surgical intervention with closed reduction under general anaesthesia were included in this study. Those with nondisplaced nasal bone fracture, a previous history of nasal bone fracture after two weeks or who had undergone septoplasty, augmentation rhinoplasty, or corrective rhinoplasty were excluded from this study. Fracture severity was evaluated according to Hwang et al.'s classification method. ${ }^{5}$ Type I simple, without displacement; type II - simple, with displacement/without telescoping (IIA - unilateral, IIAs - unilateral with septal fracture, IIB - bilateral, IIBs - bilateral with septal fracture); and type III - comminuted with telescoping or depression.
All patients underwent closed reduction with external nasal splinting under General anesthesia. After surgery, Merocele nasal tampon or ribbon gauze packing and external nasal splinting were maintained for four and seven days, respectively. The patients were followed-up for at least three months to assess the complications, such as fracture recurrence and functional abnormality in the Department. The subjective satisfaction of patients was performed by using questionnaires answered at OPD visits or in a telephone interview with patients.

0 = no improvement, 1 = mild improvement, 2 = moderate improvement, 3 = good improvement, 4 = excellent improvement

Data was entered in an excel sheet and was calculated by using SPSS 26.0 version. Percentage and frequency will be calculated by using descriptive statistics.

\section{RESULTS}

A total of 60 patients with a nasal bone fracture who underwent closed nasal bone reduction were studied. The mean age was $30.2 \pm 13.1$ years. The male to female ratio was $2.3: 1$ with a range of 10 to 67 years. Most common fractures were found to occur in 21-30 year 26 (43.3\%) followed by 31-40 years 14 (23.3\%) (Table 1$)$.

Table 1: Age wise distribution of patients

\begin{tabular}{|lcc|}
\hline Age Group & $\mathbf{n}$ & $\mathbf{\%}$ \\
\hline $1-10$ & 1 & 1.7 \\
$11-20$ & 10 & 16.7 \\
$21-30$ & 26 & 43.3 \\
$31-40$ & 14 & 23.3 \\
$41-50$ & 4 & 6.7 \\
$51-60$ & 2 & 3.3 \\
$>60$ & 3 & 5.0 \\
\hline Total & $\mathbf{6 0}$ & $\mathbf{1 0 0 . 0}$ \\
\hline
\end{tabular}

The most common cause of nasal bone fracture was road traffic accidents $25(41.6 \%)$ followed by physical assaults 18 (30.0\%), fall injuries 12 (20.0\%), other incidences 3 (5.0\%), and industrial accidents 2 (3.0\%). Forty-three (72.0\%) cases underwent closed reduction within 24 hours of those who arrived within 4-6 hour of nasal injury in the hospital and the remaining $17(28.0 \%)$ cases were reduced after 5 days of trauma. Type 2a is commonest fracture (Table 2). Concurrent fracture found in $8(13.0 \%)$ cases and it included maxillary, zygomatic, orbital, frontal bone fracture. 
Table 2: Nasal bone fracture according to Hwang Classification

\begin{tabular}{|lcc|}
\hline Type & $\mathbf{n}$ & $\mathbf{\%}$ \\
\hline $2 \mathrm{a}$ & 21 & 35.0 \\
2as & 5 & 8.3 \\
2b & 17 & 28.3 \\
$2 \mathrm{bs}$ & 10 & 16.7 \\
3 & 7 & 11.7 \\
\hline Total & $\mathbf{6 0}$ & $\mathbf{1 0 0}$ \\
\hline
\end{tabular}

Table 3: Different closed surgical intervention for nasal bone fracture

\begin{tabular}{|lcc|}
\hline Types of reduction & $\mathbf{n}$ & $\mathbf{\%}$ \\
\hline $\begin{array}{l}\text { Closed reduction } \\
\text { Closed reduction } \\
\text { septorhinoplasty }\end{array}$ & 38 & 63.3 \\
$\begin{array}{l}\text { Closed } \\
\text { Extracorporeal } \\
\text { septorhinoplasty } \\
\begin{array}{l}\text { Closed reduction } \\
\text { with septoplasty }\end{array}\end{array}$ & 7 & 16.7 \\
\hline Total & 5 & 8.3 \\
\hline
\end{tabular}

Closed reduction of nasal bone with need of septoplasty and septorhinoplasty observed in Table 3.

Complication after treatment of nasal bone fracture 3 (5.0\%) of cases olfactory disturbance, $2(3.0 \%)$ of cases had nasal obstruction. No obvious postoperative deformities were observed. Thirty-nine $(65.0 \%)$ cases experienced excellent improvement, thirteen (21.6\%) reported to have good improvement, five $(8.3 \%)$ had moderate improvement and three (5.0\%) cases had mild improvement only.

\section{DISCUSSION}

Appropriate knowledge of anatomy, physiology, and pathology of the nose helps the surgeon to treat the nasal bone fracture properly. In absence of proper treatment, it may lead to functional and aesthetic abnormalities. ${ }^{6,7}$ From the middle age, closed reduction procedure has been described in detail. ${ }^{8}$ The ultimate goal is to restore aesthetic shape and function. Though the procedure seems simple, it has a post-reduction deformity from 14 up to $50 \%$ cases. Rhinoplasty is needed to correct these irregularities which will increase the cost of the patient and needs open surgical procedure. ${ }^{1,}$ 9 With a successful initial reduction of the deformity, post op complication can be avoided.

Nasal bone fracture was commonly seen among 21-30 years in our study. Similar finding was found in a study done by Park et $a l^{10}$ and Hwang et $a l^{11}$ Male patients outnumbered females. This group are more active people in society and run high speed rides on poor quality of road. The most common cause of nasal bone fracture according to this study was road traffic accidents $41.6 \%$ followed by physical assaults $30 \%$. But study by Kim et al ${ }^{12}$ found $21.7 \%$ caused by RTA and physical assault $19.0 \%$ accounted for $38 \%$, falls accounted for $31.0 \%$, and accidents during exercise accounted for $17.0 \%$ of fractures. We know that road traffic accidents are a major problem for nasal bone fracture. Poor quality roads, potholes in the road and uneven road surface lead to more accident in our place.

With focus to fracture severity and range, we used Hwang's classification which is based on fracture severity, bone displacement, and the presence of septal fracture. Regarding the classification of nasal bone fracture, there are many different classifications like Harrison's classification ${ }^{13}$ based on associating bones and with/without displacement, and Murray et al.'s classification ${ }^{14}$ based on the pathologic criteria. General anesthesia was given in all the cases. Reduction of nasal bone can be done under sedation ${ }^{15}$ however, closed reduction under general anesthesia leads to pain relief during surgery, and for more accurate nasal bone reduction. ${ }^{10,16}$

Septorhinoplasty for acute nasal bone fracture is a new concept. In type II BS and III fracture, it's important to reduce and reconstruct, both lateral wall and septum. Corrective rhinoplasty was described with effective reduction and cosmesis by Kim et al. ${ }^{17}$ We did septorhinoplasty in those cases whose dorsum was not elevated by simply close reduction. Extracorporeal septoplasty has a role in nasal bone fracture where in situ fixation of septum was difficult.

Our study showed $65.0 \%$ cases have excellent improvement and $13(21.6 \%)$ had good improvement. Study done by Lee et al had shown improvement as excellent for 37 (74.0\%), good for 12 (24.0\%) patients, after 1 month follow up. ${ }^{18}$ It is important to maintain nasal pyramidal configuration by properly reducing the nasal bone fragment with self-supporting force. The surrounding connective tissues and both layer of periosteum should be intact to obtain good outcomes. ${ }^{19}$ 
Many protective devices prevent nasal bone fractures caused by a small amount of external force; however, these devices are not effective against higher amounts of external force. As it is retrospective study, we recommend prospective study with large sample size.

In conclusion, nasal bone fracture mostly occurs in road traffic accidents. Most fractures occur in unilateral nasal bone fracture. Careful evaluation is of paramount importance with its classification. Closed reduction with good alignment is the preferred method. Septorhinoplasty and extracorporeal septoplasty should be applied in difficult and comminuted nasoseptal fracture. It avoids future complications like external nasal deformities and crooked nose. For patients with nasal bone fracture, the concomitant reduction of the fracture and the septorhinoplasty may lead to better esthetic results through proper selection and consultation with the patient.

\section{REFERENCES}

1. Kucik CJ, Clenney TL and Phelan J. Management of acute nasal fractures. Am Fam physician 2004; 70: 1315-20. PMID: 15508543

2. Greathouse ST, Adkinson JM, Garza III R et al. Impact of injury mechanisms on patterns and management of facial fractures. J Craniofacial Surg 2015; 26: 1529-33. DOI: 10.1097/ SCS.0000000000001805

3. Swenson DM, Yard EE, Collins CL, Fields SK, Comstock RD. Epidemiology of US high school sports-related fractures, 2005-2009. Clin J Sport Med 2010; 20: 293-99. doi: 10.1097/ JSM.0b013e3181e8fae8

4. Kelley BP, Downey CR and Stal S. Evaluation and reduction of nasal trauma. Semin Plast Surg 2010; 24: 339-347. 2010/11/01. DOI: 10.1055/s0030-1269763.

5. Hwang K, You SH, Kim SG et al. Analysis of nasal bone fractures; a six-year study of 503 patients. J Craniofacial Surg 2006; 17: 261-264. PMID: 16633172. DOI: 10.1097/00001665-20060300000010

6. Atighechi $\mathrm{S}$ and Karimi G. Serial nasal bone reduction: a new approach to the management of nasal bone fracture. I Craniofac Surg 2009; 20: 49-52. 2009/01/24. DOI: 10.1097/ SCS.0b013e318190def5.

7. Ang BH, Kang HS, Han JJ et al. A retrospective clinical investigation for the effectiveness of closed reduction on nasal bone fracture. Maxillofacial Plast Reconstr Surg 2019; 41: 53.2019/12/12. DOI: 10.1186/s40902-019-0236-y.

8. Farber SJ, Nguyen DC, Parikh RP, Jang JL, Woo AS. Improving results in closed nasal reduction: a protocol for reducing secondary deformity. Plast Reconstr Surg 2017; 139: 51-9. DOI: 10.1097/ PRS.0000000000002847.

9. Kim KS, Lee HG, Shin JH, Hwang JH, Lee SY. Trend analysis of nasal bone fracture. Arch Craniofacial Surg 2018; 19: 270-74. DOI: 10.7181/ acfs.2018.02264.

10. Park HK, Lee JY, Song JM, Kim TS, Shin SH. The retrospective study of closed reduction of nasal bone fracture. Maxillofac Plast Reconstr Surg 2014; 36: 266. DOI: 10.14402/ jkamprs.2014.36.6.266.

11. Hwang $\mathrm{K}$ and You SH. Analysis of facial bone fractures: An 11-year study of 2,094 patients. Indian J Plast Surg 2010; 43: 42-48. DOI: 10.4103/0970-0358.63959.

12. Kim KS, Lee HG, Shin JH, Hwang JH, Lee SY. Trend analysis of nasal bone fracture. Arch Craniofacial Surg 2018; 19: 270. doi: 10.7181/ acfs.2018.02264

13. Harrison DH. Nasal injuries: their pathogenesis and treatment. $\mathrm{Br} J$ Plast Surg 1979; 32: 57-64. https://www.jprasurg.com/ article/0007-1226(79)90063-8/pdf

14. Murray JA, Maran AG, Busuttil A, Vaughan G. A pathological classification of nasal fractures. Injury 1986; 17: 338-44. https://doi. org/10.1016/0020-1383(86)90159-2

15. Wild D, El Alami M and Conboy P. Reduction of nasal fractures under local anaesthesia: an acceptable practice? The Surgeon 2003; 1: 45-47. https://doi.org/10.1016/S1479-666X(03)80009-4

16. Haug RH and Prather JL. The closed reduction of nasal fractures: an evaluation of two techniques. J Oral Maxillofac Surg 1991; 49: 1288-92. DOI:https://doi.org/10.1016/0278-2391(91)903045

17. Kim J, Jung HJ and Shim WS. Corrective septorhinoplasty in acute nasal bone fractures. Clin Exp Otorhinolaryngol 2018; 11: 46. doi: 10.21053/ceo.2017.00346

18. Lee BM and Han DG. Acute Bone Remodeling after Reduction of Nasal Bone Fracture on Computed Tomography Imaging. Arch Craniofacial Surg 2014; 15: 63-9. 2014/08/14. DOI: 10.7181/acfs.2014.15.2.63.

19. Dahlin C, Linde A, Gottlow J, Nyman S. Healing of bone defects by guided tissue regeneration. Plast Reconstr Surg 1988; 81: 672-6. DOI: 10.1097/00006534-198805000-00004. 